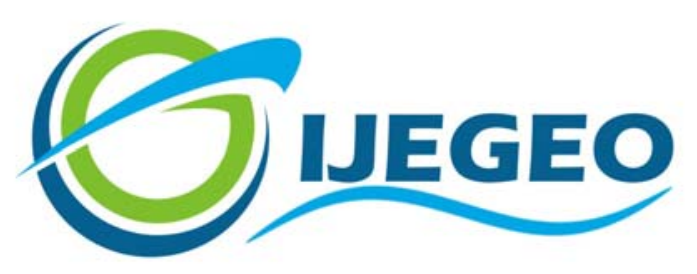

International Journal of Environment and Geoinformatics (IJEGEO) is an international, multidisciplinary, peer reviewed and certified open access journal.

\title{
Determination of the Olive Trees with Object Based Classification of Pleiades Satellite Image
}

\author{
Uğur Algancı, Elif Sertel and Şinasi Kaya \\ Editors \\ Prof. Dr. Cem Gazioğlu, Prof. Dr. Dursun Zafer Şeker, Prof. Dr. Ayşegül Tanık, \\ Prof. Dr. Şinasi Kaya, Assist. Prof. Dr. Volkan Demir

\section{Scientific Committee (2018)} \\ Dr. Abdullah Aksu, Prof. Dr. Bedri Alpar, Prof. Dr. Gülşen Altuğ, Prof. Dr. Lale Balas, Prof. Dr. \\ Can Balas, Prof. Dr. Levent Bat, Prof. Dr. Bülent Bayram, Prof. Dr. Nuray Çağlar, Prof. Dr. \\ Jadunandan Dash, Prof. Dr. A. Evren Erginal, Dr. Dieter Fritsch, Dr. Amin Gharehbaghi, Assoc. \\ Prof. Dr. Tolga Görüm, Prof. Dr. Melike Gürel, Dr. Hakan Kaya , Prof. Dr. Fatmagül Kılıı̧, Assoc. \\ Prof. Dr. Maged Marghany, Prof. Dr. Nebiye Musaoğlu, Prof. Dr. Masafumi Nakagawa, Prof. Dr. \\ Haluk Özener, Prof. Dr. Erol Sarı, Prof. Dr. Elif Sertel, Prof. Dr. Nüket Sivri, Assoc. Prof. Dr. \\ Füsun Balık Şanlı, Prof. Dr. Uğur Şanlı, Assoc. Prof. Dr. Hasan Özdemir, Prof. Dr. Taşkın \\ Kavzoğlu, Msc. Mustafa Üstüner, Assoc. Prof. Dr. Oral Yağc1, Prof. Dr. Seyfettin Taş, Assoc. Prof. \\ Dr. Ömer Suat Taşkın, Assoc. Prof. Dr. İ. Noyan Yılmaz, Dr. Baki Yokeş, Dr. Sibel Zeki
}




\title{
Determination of the Olive Trees with Object Based Classification of Pleiades Satellite Image
}

\author{
Uğur Algancı ${ }^{*}$, Elif Sertel, Şinasi Kaya \\ Istanbul Technical University, Geomatics Engineering Department, 34469 Sarıer Istanbul TR \\ Corresponding author* \\ Tel :+902122853810 \\ E-mail : alganci@itu.edu.tr $\quad$ Accepted: 01 July 2018
}

\begin{abstract}
Identification of fruit trees and determination of their spatial distribution is an important task for several agricultural activities including fruit yield estimation, irrigation planning, disease management and supporting agricultural policies. This research aims to determine spatial distribution of olive trees at parcel level by using geographic object based image analysis (GEOBIA) and very high resolution satellite images. A pilot area located in the Aegean region of Turkey was selected to conduct research considering the massive amount of olive production within the area. GEOBIA based decision-tree classification was applied to accurately map perennial crop parcel boundaries. After applying multi-resolution segmentation to create image objects, thresholds determined from spectral properties of image objects were integrated into the decision tree to ensure accurate mapping of olive trees. Accuracy assessment was conducted by comparing a highly accurate parcel database with classification results and efficiency of parcel identification and areal information derivation were evaluated. Our results indicated that, decision-tree oriented GEOBIA classification provided sufficient results for determination of olive trees with 90 percent classification accuracy and differentiating them from nonvegetated areas and annual crops. Area estimation and parcel detection performances of the method were also acceptable by providing 0.11 and 0.08 relative errors respectively.
\end{abstract}

Keywords: Area Estimation, Object Based Classification, Olive Tree Identification, Parcel Level Analysis, Pleiades Satellite Image

\section{Introduction}

Farming of the perennial crops has a great importance to meet global agricultural demands and to support economic growth of the countries. Turkey is one of the major contributors of olive production, ranking fourth with 1,768,000 tons in 2014 (FAO, 2017). The Aegean region of Turkey is dominant in olive production while citrus fruit production has the majority in Mediterranean region. Identification of perennial crops and determination of their spatial distribution is an important task for several agricultural activities including fruit yield estimation, irrigation planning, disease management and supporting agricultural policies such as planning farmer subsidies and verifying their claims. Thus, detection of the spatial distribution of perennial crops and monitoring the up-to-date situation of them becomes indisputably important.
At this point, remote sensing technology is proven to be a significant and efficient information source for agricultural applications and crop mapping (Beach et al., 2008; Tansey et al., 2009). Satellite images provide identifiable spectral information for different agricultural landscapes depending on their resolution properties (Ozdogan and Woodcock, 2006; Pena-Barragan et al., 2011; Alganc1 et al., 2013). Especially in the last decade, very high resolution (VHR) satellite image data with $0.5-5 \mathrm{~m}$ spatial resolution range has enabled high accuracy on crop mapping and area estimation of agricultural parcels. High spatial resolution and increased radiometric sensitivity of remote sensing satellites and aerial photographs also increased the determination capability of perennial crops due to enhancement in textural and spectral information derived from these data (PenaBarragan et al., 2004; Okuş et al., 2004, 
Johansen et al., 2009; Heller et al., 2012, Kaya et al., 2015).

Developments in sensor design and technology has pushed the analysis techniques to be efficient and reliable. Most of the pixel based classification algorithms rely on only the spectral properties of the image bands and often fail to produce a reliable thematic map result due to within parcel heterogeneity especially with VHR satellite images. To address this problem, geographic object based image analysis (GEOBIA) algorithms have been developed, that consider textural and shape properties and geometric relations of the objects defined by segmentation process in addition to spectral values of the pixels (Duveiller and Defourny, 2010; Johansen et al., 2010).

This research aims to determine spatial distribution and areal extent of perennial crops in the Edremit region located in Balikesir Province, Turkey using object based image analysis and very high-resolution Pleiades imagery. Geometric correction, segmentation and decision tree based object oriented classification were applied to image data in order to determine the non- vegetated, annual crop and perennial crop classes in a $7.5 \times 7.5$ $\mathrm{km}$ test area. A simple hierarchical classification ruleset based on mean spectral values, maximum difference value and standard nearest neighbor characteristics of the image objects was integrated into the classification process. Area estimation errors were measured by areal comparison of classification results with a highly accurate parcel vector data. Results of classification were also evaluated with accuracy assessment using stratified random points.

\section{Materials and Methods}

\section{Study Area}

The study area is located in Balikesir province, which has a major contribution to olive production of Turkey. This province is located in the Aegean part of Turkey and is very suitable for olive production with its plain terrain and Mediterranean climate that is suitable for olive phenology. According to Turkish Statistical Institutes report in 2014, 82,000 hectares for area is covered with olive trees and approximately 150,000 tons of olive was produced inside the borders of the province (TUIK, 2017). The Edremit region that was selected as test area for this study is located in the west side bay of the province and contains large olive tree plantations (Figure 1).

\section{Materials}

Pleiades 1A satellite, launched on December 16,2011 , is the first satellite of Pleiades $1 \mathrm{~A}$ and Pleiades 1B constellation that enables $0.5 \mathrm{~m}$ high spatial resolution and $20 \times 20 \mathrm{~km}$ coverage area with 1 frame. These satellites include $2 \mathrm{~m}$ multispectral sensors in blue, green, red and NIR regions in addition to $0.5 \mathrm{~m}$ panchromatic sensor (AIRBUS, 2017). The image used in this study acquired on 20 October 2014, which corresponds to green fruit development (3rd) stage of olive in that region. The second data source for this study was the parcel vector data of the study area. This parcel vector generated by digitization of aerial photos and VHR images and using the cadastral maps as base by Ministry of Agriculture.

\section{Preprocessing}

The Pleiades 1A image of the study area obtained as ortho-rectified and pan-sharpened for this research. The image was converted to top of atmosphere (ToA) reflectance for radiometric calibration and stored as 16-bit data. According to manual analysis and measurements, location offset up to $12 \mathrm{~m}$ observed between image and parcel vector data. Thus, image was geometrically corrected using a first order polynomial model and with 12 ground control points (GCP) that were collected from parcel vector data. After a visual check for the locational overlap of the satellite image with parcel vector, the image was subset by a $7.5 \mathrm{~km}$ by $7.5 \mathrm{~km}$ square polygon in order to obtain the test area data. The test area represents a land use/cover distribution that consists of non - vegetated areas (urban areas and empty agricultural lands) and vegetated areas (perennial croplands and annual croplands).

\section{Geographic Object Based Image Analysis}

Land use and cover mapping with VHR images using pixel based algorithms have been asserted not to be efficient enough due to within object 
heterogeneity as objects consist of too many pixels (van der Sande et al., 2003; Zhou et al., 2008).

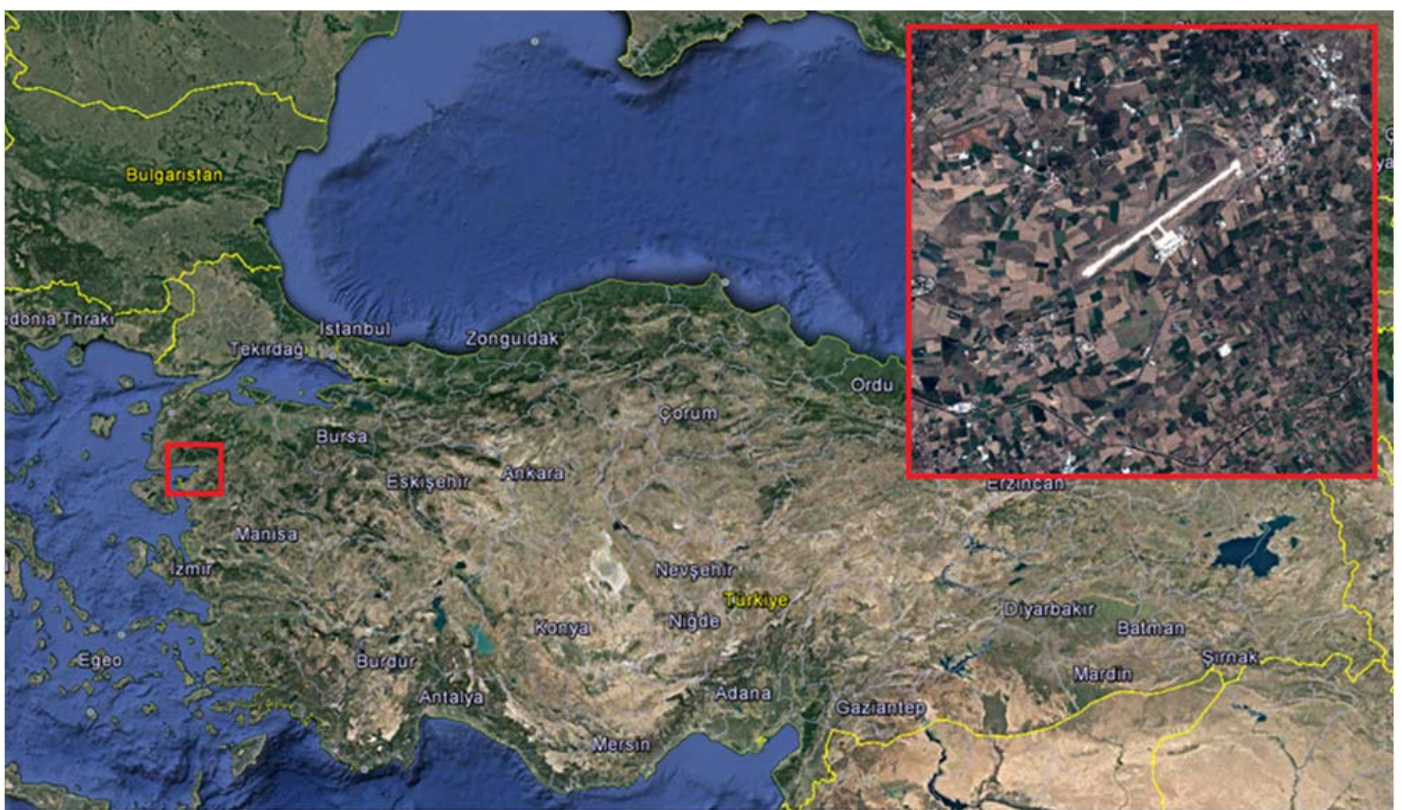

Fig 1. Location of the study area over Turkey Landsat mosaic, Base image from Google Earth $\mathbb{C}$ 2017 and closer look from Pleiades

Unlike the pixel based classification algorithms, GEOBIA algorithms consider the elementary unit as object or segment that is defined by segmentation (Benz et al., 2004). This approach aims to divide a satellite image into meaningful homogenous polygons (segments) that, one or combination of multiple segments represent the actual ground object. Afterwards, these segments are classified according to their spectral or textural properties that define the classes. Thus, in VHR image classification, GEOBIA techniques have become very effective and stable methods (Kim et al., 2009).

Scale and heterogeneity parameters are the main parameters that affect the results of segmentation process. Size of the image objects are defined by the scale parameter thus, these parameters are relatively changeable according to the data used and size characteristics of the objects in the study area. Therefore, it can be asserted that there is a relationship between scale - spatial resolution and scale - object size. In addition, heterogeneity parameter controls the object merging decision according to spectral and/or non-spectral input data (Matheiu and Aryal, 2005; Blaschke, 2010).

The GEOBIA classification process was performed using Definiens Ecognition $(\mathcal{C}$ commercial software. As a first step of GEOBIA approach, image objects were created from Pleiades 1A image using multiresolution segmentation algorithm. In the first step of segmentation, all bands of the Pleiades $1 \mathrm{~A}$ image were weighted proportional to standard deviation value of the pixels constituting each image band. Weights found to be $0.4,0.5,0.6$ and 1 for the blue, green, red and near infrared bands of the image respectively.

Afterwards, other segmentation parameters such as scale factor, shape/color and compactness/smoothness were tested experimentally and results were visually compared with the original image to find out the optimal parameter set in terms of object definition accuracy and total segment amount. According to the results of this analysis, scale, shape and compactness parameters found to be 220, 0.7 and 0.5, respectively. Segmentation 
results obtained from the optimum parameter set and corresponding classes for each segment are given in Figure 2.

After the segmentation process, a hierarchical rule -based decision tree was developed to

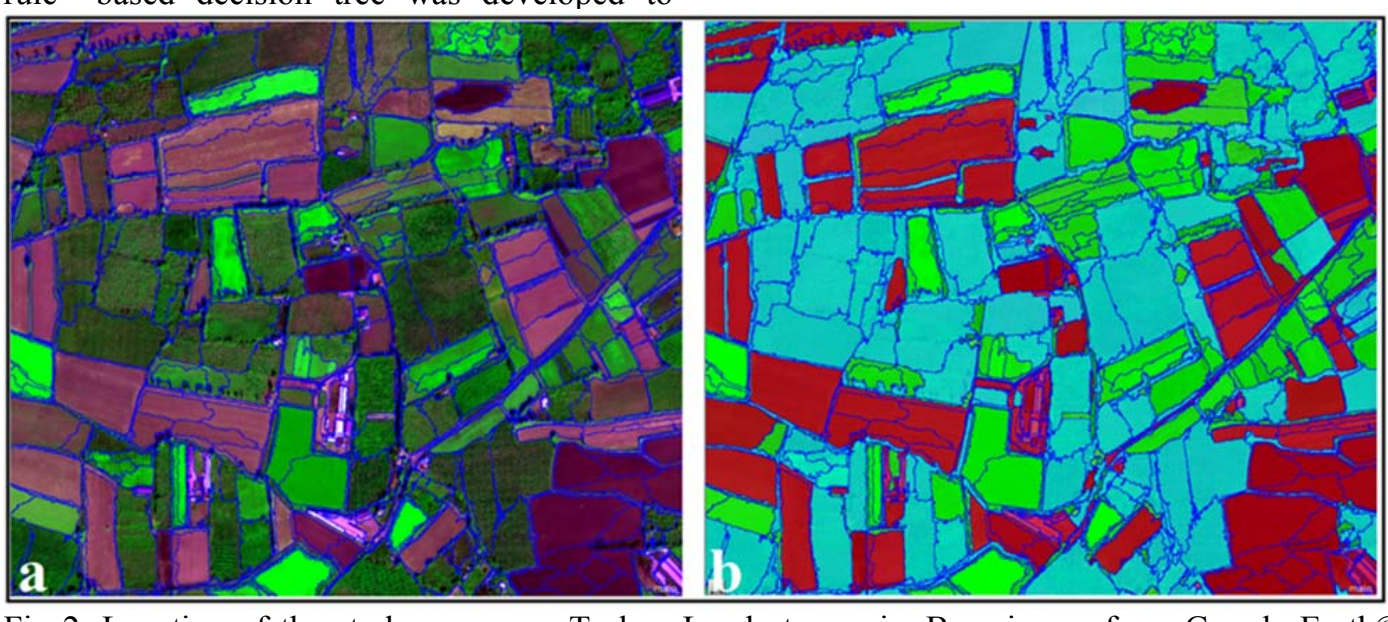

Fig 2. Location of the study area over Turkey Landsat mosaic, Base image from Google Earth ( 2017 and closer look from Pleiades.

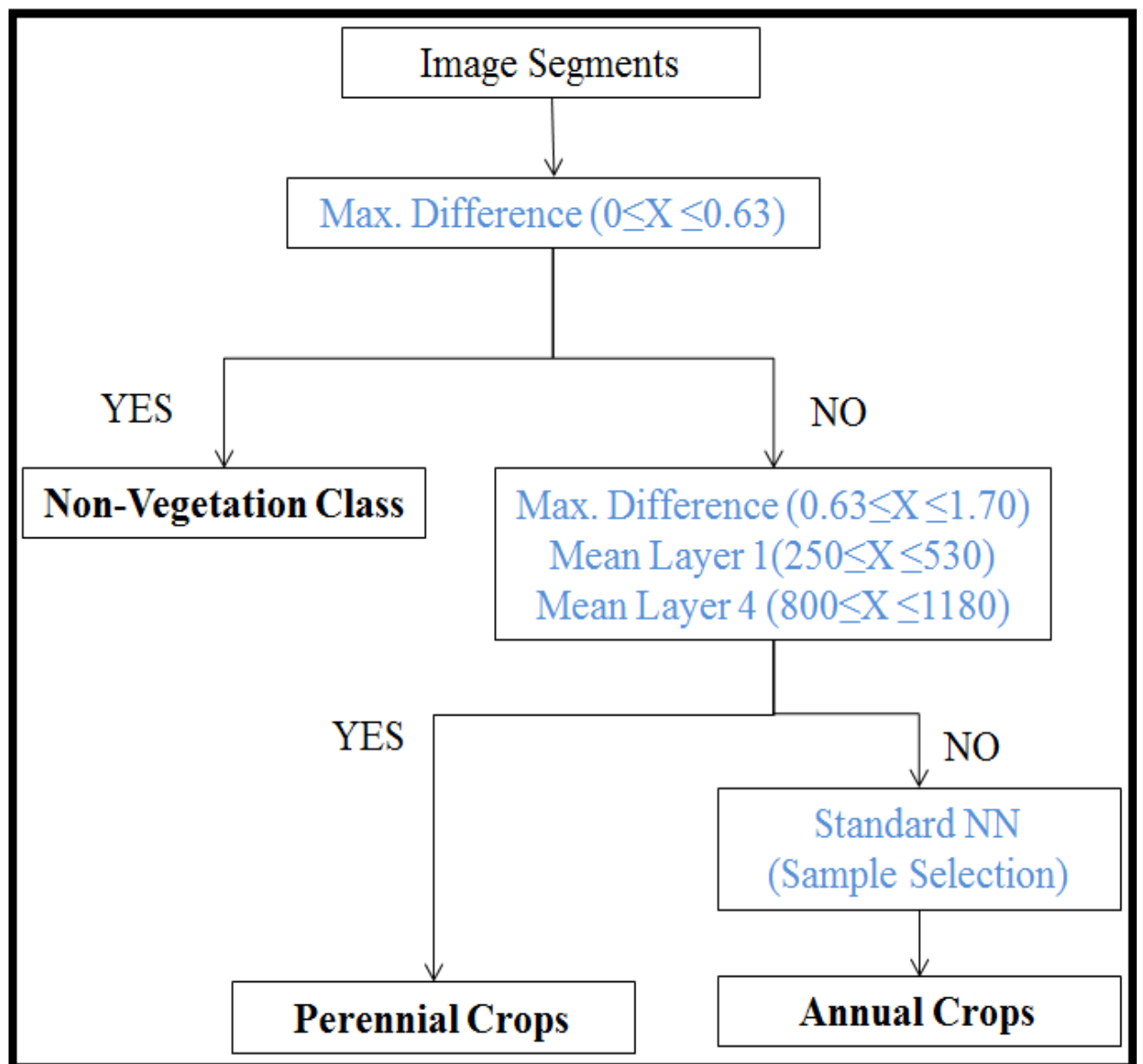

Fig 3. Flowchart of the decision tree ruleset that developed for classification. identify non-vegetated areas and vegetated areas first and then perennial crops and annual crops within vegetated areas. 
The ruleset was designed to extract nonvegetation class using a threshold-based definition of a maximum difference parameter. Secondly, perennial crops were extracted from the remaining image objects with threshold definition of Mean Layer 1 (red band), mean layer 4 (NIR band) and maximum difference parameters considering the fact that Red and NIR parts of the electromagnetic spectrum are sensitive to vegetation related categories. Lastly, a standard nearest neighbor algorithm was applied to the remaining objects with manual sample selection for determination of annual crops. Flowchart of the classification decision tree is given in Figure 3.

\section{Accuracy Assessment}

For this study, two different accuracy assessment methods were performed. In the first method, class vectors belonging to different land cover types were compared to parcel vector database of the pilot region for area-based comparison. After the areal comparison, relative errors in area estimation and parcel identification were calculated for perennial crop class as accuracy metric. In the second accuracy analysis, 100 stratified random points were used to retrieve the user, producer accuracy metrics (Story and Congalton, 1986) and kappa statistics (Cohen, 1960).

\section{Results and Discussion}

Results of this study showed that, VHR images provided reliable geographic information for spatial distribution and boundary delineation of perennial and annual crops and their area calculation (Figure 4). In addition, decision tree based GEOBIA classification including different thresholds of spectral characteristics provided a semi - automatic approach for identification of agricultural parcel boundaries and related crop types within that parcel. Parcel vector data from the governmental database and class parcel data from classification results were compared in order to derive the parcel identification and area estimation metrics and to perform point based accuracy assessment.
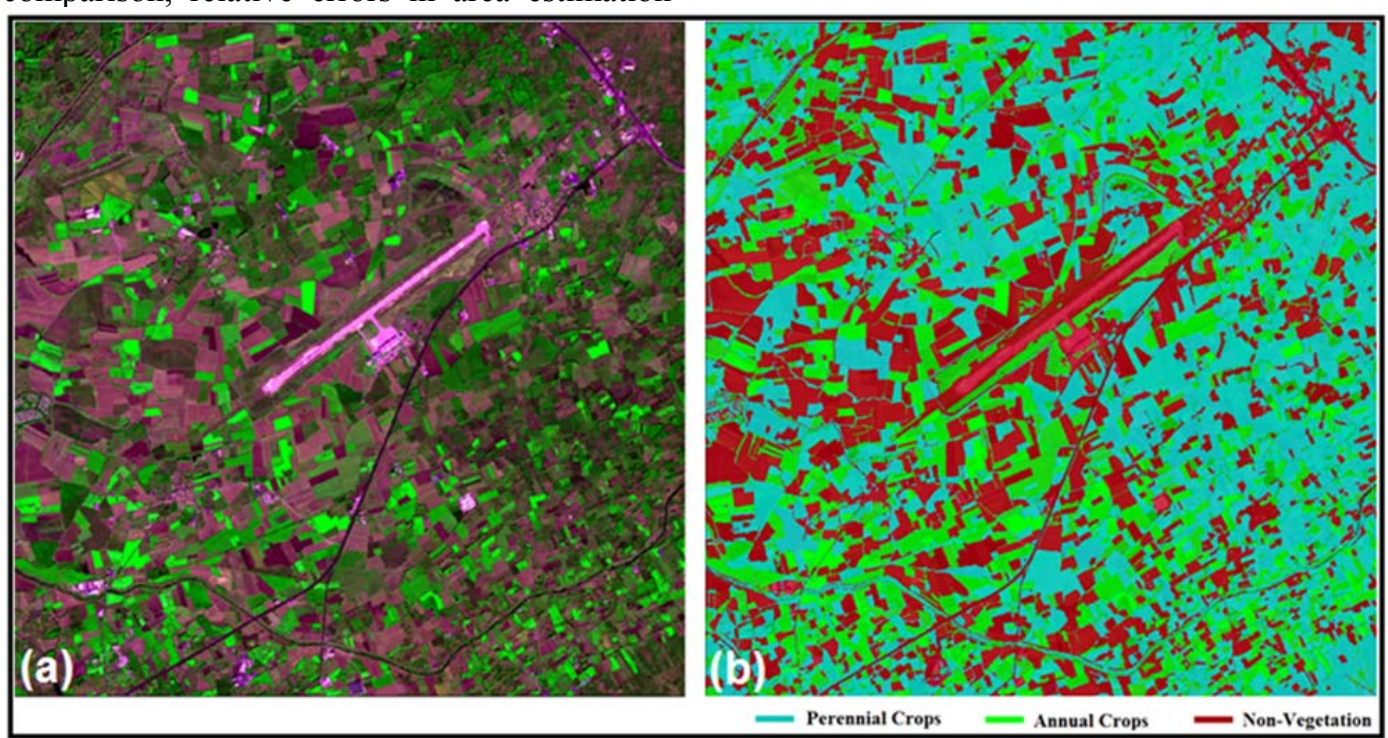

Fig 4. Original Pleiades image (Red/NIR/Blue) and OBC classification result of test site

According to test site classification results, relative error of area estimation for crop types did not exceed 0.11 thus provided approximately $89 \%$ accuracy in area estimation (Table 1). Moreover, parcel identification performance of the GEOBIA method was considerably acceptable with a relative error of
0.08. Lastly, point based classification accuracy assessment results showed that land cover types can be classified between $85-90 \%$ accuracy. In specific, perennial crops were identified with $90 \%$ producers and user's accuracy (Table 2 ). Although class identification and area estimation results are satisfactory, boundary 
identification of perennial crop parcels failed in some regions especially where there are no separating boundary element exists between parcels. Narrow pathways between parcels could not be identified by segmentation considering the fact that they are mostly covered with vegetation of the cultivated areas. Thus, neighbor parcels with same crop type were merged in segmentation. However, it can be strongly asserted that region based perennial crop area estimation was successful.

Reference parcel data was the second factor of lower accuracy of parcel determination. There had been mismatching problems between classification based vector data and reference parcel data since this vector data is based on cadastral maps. Inherently, cadastral parcel boundaries are prepared according to the ownership information instead of actual usage information. Moreover, update frequency of this data is low so new agricultural fields or new land use characteristics were not completely integrated into this data and it does not always represent the current cultivation pattern. Thus, we used only matching parcels for point based accuracy assessment.

Definition of the optimal segmentation parameter set is another important output of this study. Although segmentation parameters are changeable and could be determined experimentally, some intervals can be defined for specific land cover / use types. The parameter set defined for the test area has the potential to be used for broader areas in nearby regions, as parcel size and shape characteristics will be similar. At this point, it is worth noting that textural structure of the perennial crops is a key factor to differentiate them from their surroundings in the segmentation process and this information can be derived efficiently from the VHR satellite images. Thus, VHR satellite images or aerial ortho-photos seem to be reliable remotely sensed data sources for perennial crop classification with their capability of providing the textural information within parcels.

Table 1. Area estimation and parcel metrics of olive trees

\begin{tabular}{|l|l|l|l|l|l|l|}
\hline \multirow{2}{*}{$\begin{array}{l}\text { Crop Type } \\
\text { (Perennial) }\end{array}$} & \multicolumn{3}{|c|}{ Area Estimation } & \multicolumn{3}{c|}{ Parcel Identification } \\
\cline { 2 - 7 } & Class (ha) & Parcel (ha) & Er & Class (Number) & Parcel (Number) & Er \\
\hline Olive Tree & 1.935 & 2.171 & 0.11 & 2.688 & 2.931 & 0.08 \\
\hline
\end{tabular}

Table 2. Point based accuracy assessment results for the test area

\begin{tabular}{|l|l|l|l|l|l|l|}
\hline Class & Ref Total & Class Total & $\begin{array}{l}\text { Num. } \\
\text { Correct }\end{array}$ & $\begin{array}{l}\text { Prod. } \\
\text { Ac }\end{array}$ & User Ac & Kappa Sta \\
\hline Non-vegetation & 30 & 31 & 27 & $90.00 \%$ & $87.10 \%$ & 0.8157 \\
\hline Perennial & 40 & 40 & 36 & $90.00 \%$ & $90.00 \%$ & 0.8333 \\
\hline Annual & 30 & 29 & 26 & $86.67 \%$ & $89.66 \%$ & 0.8522 \\
\hline
\end{tabular}

\section{Conclusion}

Identification of perennial crops such as olive trees is an important task to provide valuable information that can be used in subsidy management and yield estimation. To this end, VHR satellite images are useful for individual identification of olive tree parcels. Our research results showed that GEOBIA classification of VHR satellite images provides accurate, reliable and up to date information in perennial crop mapping and area estimation. For our research, Pleiades
1A satellite images found to be appropriate as a data source for olive tree detection. At this point, in situations where multi-temporal imagery is unavailable, the image acquisition date and its suitability with the phenological stage is also important. Period selection in this research enabled a natural spectral differentiation of olive trees from surrounding landscape as annual crop plantation was minimal and broad- leaved forests has started to yellowing. Moreover, threshold based hierarchical classification rule set developed in this research mainly 
used the Red and NIR bands of the satellite images, so it can be asserted that any VHR satellite imagery including these bands will be appropriate for such kind of analysis.

\section{Acknowledgements}

Authors acknowledge the support of "Istanbul Technical University - Application and Research Center for Satellite Communication and Remote Sensing (ITU CSCRS)" by providing the Pleiades 1A satellite image and the support of "Republic of Turkey Ministry of Food, Agriculture and Livestock" by providing the agricultural parcel database.

\section{References}

AIRBUS, 2017. Pleiades Satellite Imagery. http://www.geoairbusds.com/pleiades/ (Accessed 4 April 2017).

Alganc1, U., Sertel, E., Ozdoğan, M., Örmeci, C. 2013. Parcel-Level Identification of Crop Types Using Different Classification Algorithms and MultiResolution Imagery in Southeastern Turkey. Photogrammetric Engineering and Remote Sensing, 79(11), 1053-1065.

Beach, R.H., DeAngelo, B.J., Rose, S.K., Li, C., Salas, W., Del Grosso, S.J. 2008. Mitigation potential and costs for global agricultural greenhouse gas emissions. Agricultural Economics, 38, 109-115.

Benz, U.C., Hofmann, P., Willhauck, G., Lingenfelder, I., Heynen, M. 2004. Multiresolution, object-oriented fuzzy analysis of remote sensing data for GIS ready information. ISPRS Journal of Photogrammetry and Remote Sensing, 58, 239-258.

Blaschke, T. 2010. Object based image analysis for remote sensing. ISPRS Journal of Photogrammetry and Remote Sensing, 66(1), 2-16.

Cohen, J. 1960. A coefficient of agreement for nominal scales. Educational and Psychological Measurement, 20, 37-46.

Duveiller, G., Defourny, P. 2010. A conceptual framework to define the spatial resolution requirements for agricultural monitoring using remote sensing. Remote Sensing of Environment, 114, 2637-2650.
FAO, 2017. Agricultural Statistics of the Food and Agriculture Organization of the United

Nations,http://www.fao.org/faostat/en/\#da ta/QC. (Accessed 20 January 2017.)

Heller, E., Rhemtulla, J.H., Lele, S., Kalacska, M., Badiger, S., Sengupta, R., Ramankutty, N. 2012. Mapping crop types, irrigated areas, and cropping intensities in heterogeneous landscapes of southeastern India using multi-temporal medium-resolution imagery: implications for assessing water use in agriculture. Photogrammetric Engineering and Remote Sensing, 78(8), 815-827.

Johansen, K., Arroyo, L.A., Phinn, S., Witte, C. 2010. Comparison of geo-object based and pixel-based change detection of riparian environments using high spatial resolution multi-spectral imagery. Photogrammetric Engineering and Remote Sensing, 76(2), 123-136.

Johansen, K., Phinn, S., Witte, C., Philip, S., Newton, L. 2009. Mapping banana plantations from object-oriented classification of SPOT-5 imagery. Photogrammetric Engineering and Remote Sensing, 75(9), 1069-1081.

Kaya, S., Gazioğlu, C., Sertel, E., Şeker, D.Z., and Alganc1, U., (2015). Rapid determination of land use/cover changes using data fusion. The 36th Asian Conference on Remote Sensing "Fostering Resilient Growth in Asia", Metro Manila, Filipinler, 19-23 October 2015.

Kim, M., Madden, M., Warner, T.A. 2009. Forest type mapping using object-specific texture measures from multispectral Ikonos imagery: segmentation quality and image classification issues. Photogrammetric Engineering and Remote Sensing, 75(7), 819-829.

Mathieu, R., Aryal, J. 2005. Object-oriented classification and Ikonos multispectral imagery for mapping vegetation communities in urban areas. Proceedings of SIRC 2005 - The 17th Annual Colloquium of the Spatial Information Research Centre University of Otago, Dunedin, New Zealand November 24th25th 2005. 
Okuş, E., Sur, HI, Yüksek, A., Yılmaz, IN, AslanYımaz, A., Karhan, SÜ, Öz, Mİ, Demirel, N, Taş, S, Altıok, H. and Gazioğlu, C. (2004). Datça-Bozburun özel çevre koruma bölgesinin denizsel ve kıyısal alanlarının biyolojik çeşitliliğinin tespiti projesi, Ankara: TC Çevre ve Orman Bakanlığı ÖÇKK Başkanlığı.

Özdoğan, M., Woodcock, C.E. 2006. Resolution dependent errors in remote sensing of cultivated areas. Remote Sensing of Environment, 103, 203-217.

Peña-Barragán, J.M., Jurado-Expósito, M., López-Granados, F., Atenciano, S., Sánchez de la Orden, M., García-Ferrer, A., García-Torres, L. 2004. Assessing land-use in olive groves from aerial photographs. Agriculture, Ecosystems and. Environment, 103, 117-122.

Peña-Barragán, J.M., Ngugi, M.K., Plant, R.E., Six, J. 2011. Object-based crop identification using multiple vegetation indices, textural features and crop phenology. Remote Sensing of Environment, 115, 1301-1316.

Story, M., Congalton, R.G. 1986. Accuracy assessment: a user's perspective. Photogrammetric Engineering and Remote Sensing, 52, 397-399.

Tansey, K., Chambers, I., Anstee, A., Denniss, A., Lamb, A. 2009. Objectoriented classification of very high resolution airborne imagery for the extraction of hedgerows and field margin cover in agricultural areas. Applied Geography, 29, 145-157.

TUIK, 2017. Crop Production statistics. http://tuikapp.tuik.gov.tr/bitkiselapp/bitki sel ing.zul. (Accessed 29 March 2017).

van der Sande, C.J., de Jong, S.M., de Roo, A.P.J. 2003. A segmentation and classification approach of IKONOS-2 imagery for land cover mapping to assist flood risk and flood damage assessment. International Journal of Applied Earth Observation and Geoinformation, 4, 217229.

Zhou, W., Troy, A. 2008. An object-oriented approach for analyzing and characterizing urban landscape at the parcel level. International Journal of Remote Sensing, 29(11), 3119-3135. 